\title{
Waters encroaching
}

\author{
Weather is unpredictable and storms such as those seen in June have always occurred. Now climate \\ change, in the form of sea-level rise, is increasing the risk of damage along the coasts and has \\ implications for insurance and preparedness.
}

June 2016 started off with storms - Europe was hit by fierce storms (which included lightning strikes), resulting in floods as a large low-pressure system sat over the continent. In Paris, the Seine rose to its highest level since 1910, with the peak estimated to be $6.5 \mathrm{~m}$ - high enough to require relocation of art from the lower levels of the Louvre and Musée d'Orsay. Another severe storm event hit the east coast of Australia, with striking images coming from Sydney, where a storm surge decimated Collaroy Beach, resulting in homes teetering on the edge, and a swimming pool falling into the sea. It has been reported that the beach had narrowed by $50 \mathrm{~m}$ following the storm $^{1}$. A low pressure trough and king tides were responsible for the storm and the associated surge, but a raised sea level would have pushed the surge higher still.

Although extreme low-pressure systems have formed historically and resulted in storm events, combining these with rising sea levels increases the risk of damage, not from the storm itself but the resulting storm surge, coastal flooding and inundation.

Human influence on sea-level rise has increased in recent years. In this issue, on page 701 Aimée Slangen and colleagues evaluate the influence of natural and anthropogenic forcings on sea-level rise. They conclude that anthropogenic forcings have dominated in recent years, and contributed to more than $70 \%$ of sea-level rise in 2000. This is a dramatic increase from a contribution of $15 \%$ prior to 1950, and if the whole period 1900-2005 is considered, anthropogenic forcings contribute $38 \%$, highlighting the increase over that timeframe. As Sönke Dangendorf notes in the associated News and Views, on page 661: "natural sea-level variability can significantly mask or amplify anthropogenic long-term changes with serious impacts on our coasts."

By 2100, global sea-level rise is predicted to lie somewhere between 0.52 and $0.98 \mathrm{~m}$ (under a high emissions scenario) according to the IPCC Fifth Assessment Report ${ }^{2}$ - but sea-level rise will not stop in 2100. The rise will be ongoing (termed as virtually certain in the assessment) due to the thermal expansion of sea water. Taking

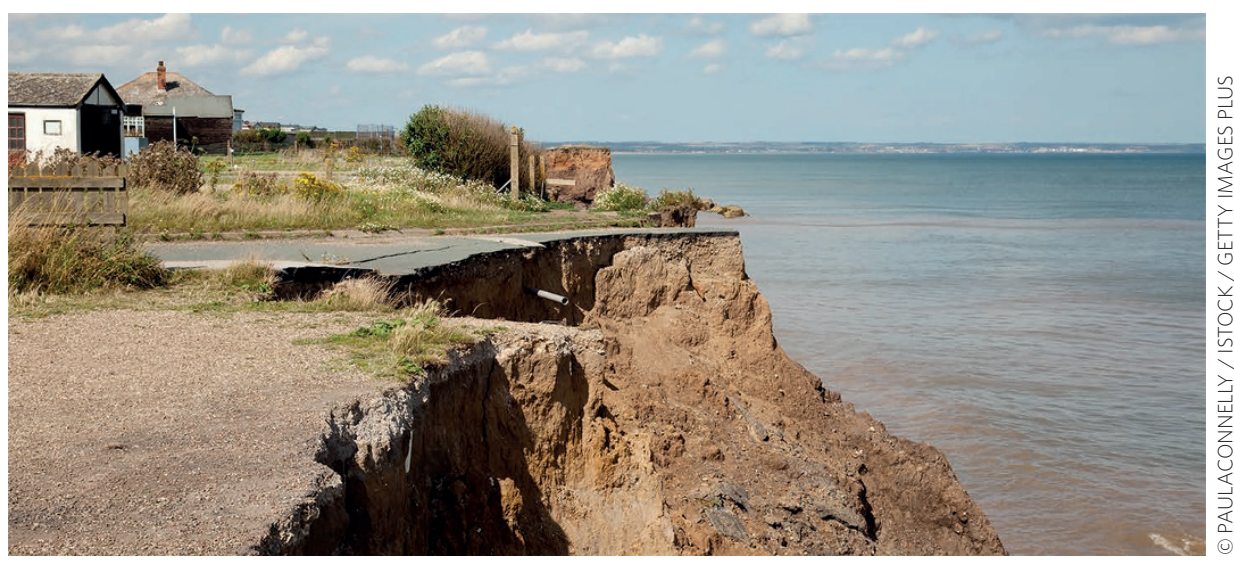

a longer-term view, a recent Perspective ${ }^{3}$ looked at the millennial scale and suggested that on the basis of the $470 \mathrm{PgC}$ released upto the year 2000, we are committing to a global sea-level rise between 1.2 and $2.2 \mathrm{~m}$. The authors note that release of an additional $470 \mathrm{PgC}$ into the atmosphere will commit us to around nine metres of sea-level rise, with large contributions from partial loss of the Antarctic ice sheet; which has the potential to contribute approximately $58 \mathrm{~m}$ of sea-level rise.

There is bad news for residents who have suffered loss and damage in these storms insurance will not always cover the cost due to exclusions for acts of god and actions of the sea. As events such as those seen this month (and other extreme events) increase in frequency and severity, it will become more difficult to secure insurance in coastal areas and planning permission to build on flood plains and seaside areas.

In the United States, the Federal Emergency Management Agency, who administer the National Flood Insurance Program (NFIP), provide detailed flood hazard maps (http://msc.fema.gov/portal). The NFIP aims to encourage homeowners and small businesses to have insurance by providing an affordable option. In 2012 they held 5.6 million policies, insuring US\$1.25 trillion of assets. With global annual flood losses estimated at US $\$ 6$ billion in 2005 - and projected to increase to US $\$ 52$ billion by $2050^{4}-$ insurance is a risky game to be in. How long such a scheme like NFIP can exist with increasing risk is uncertain, as the premiums are low and the scheme operates at a loss. Such ventures will require local and federal support to continue.

At the local level, Miami-Dade County, Florida - which, due to its low-lying topography, high population and location is at high risk from sealevel changes - is moving in the right direction, implementing steps to address climate change risks by evaluating infrastructure and has appointed a Chief Resilience Officer.

According to a study on page 691 by Matthew Hauer and colleagues, Florida needs to be concerned. They predict the number of US coastal residents at risk from sea-level rise in 2100 , and find that nearly half of the at-risk population are resident in Florida.

The coastal areas of the world are densely populated and humanity seems to have an affinity for seaside living. As the world changes, we need to prepare and adapt if we want to continue to enjoy life in close proximity to the ocean.

\footnotetext{
References

1. Collaroy Beach 'loses 50 metres' after Australia storm. BBC News (accessed 7 June 2016); http://www.bbc.co.uk/news/ world-australia-36457848

2. Church, J. A. et al. in Climate Change 2013: The Physical Science Basis (eds Stocker, T. F. et al.) Ch. 13 (IPCC, Cambridge Univ. Press, 2013).

3. Clark, P. U. et al. Nature Clim. Change 6, 360-369 (2016).

4. Hallegatte, S., Green, C., Nicholls, R. J. \& Corfee-Morlot, J. Nature Clim. Change 3, 802-806 (2013).
} 